\title{
Pulmonary oedema after lithotripsy in a patient with hypertrophic subaortic stenosis
}

Pulmonary oedema in a patient with hypertrophic subaortic stenosis undergoing extracorporeal shock wave lithotripsy is described. This event occurred upon emergence from the bath. It is suggested that pulmonary oedema followed emergence because of a reduction in central venous pressures and a decrease in preload which led to transient dynamic obstruction. Treatment with beta adrenergic blockade reduced outflow tract obstruction. Anaesthetists should be aware of the haemodynamic consequences of immersion and emersion with extracorporeal shock wave lithotripsy.

Cette observation décrit un cas d'oedème pulmonaire chez une patiente porteuse d'un rétrécissement aortique sous-valvulaire qui subit une lithotripsie par ondes de choc. Cette complication est survenue à la sortie de la piscine. On suggère que l'étiologie de cet accident pourrait être la baisse de la tension veineuse centrale suivie d'un chute de la précharge qui a provoqué une obstruction dynamique du retour veineux. Le traitement inhibiteur $\beta$-adrénergique a réduit l'obstruction à l'écoulement veineux sanguin. Les anesthésistes doivent être alertés sur les conséquences de limmersion et de lémersion de la lithotripsie par ondes de choc.

Extracorporeal shock wave lithotripsy (ESWL) is a well established treatment for renal and ureteral calculi. It has a low morbidity, reduces hospital stay, and has a high success rate. ${ }^{1}$ The Dornier immersion system consists of

\section{Key words}

COMPLICATIONS: oedema, pulmonary; HEART: aortic valve, hypertrophic stenosis; SURGERY: urology, lithotripsy.

From the Department of Anesthesiology, North Shore University Hospital, Manhasset, N.Y.

Address correspondence to: Dr. LaPorta, Department of

Anesthesiology, North Shore University Hospital, 300

Community Drive, Manhasset, N.Y. 11030.

Accepted for publication 23rd January, 1993. a patient gantry which places the patient in a water bath so that the kidney stone lies above a focused shock wave generated by a spark plug. New non-immersion systems are available but they do not have as high an energy level as an immersion system. It is important that the anaesthetist understand the haemodynamic changes induced by immersion and emersion of anaesthetized patients from a tank of water. We report a case of pulmonary oedema associated with removing a patient from an ESWL bath.

\section{Case report}

The patient, a 53-yr-old woman, was scheduled to undergo ESWL for treatment of a left ureteral calculus. She was morbidly obese (weight $145 \mathrm{~kg}$, height $160 \mathrm{~cm}$ ), and had a history of hypertrophic subaortic stenosis (IHSS), diagnosed in 1969 by cardiac catherization, ventricular ectopy with an episode of supraventricular tachycardia in 1987, and mild asthma. There was no evidence of mitral regurgitation. She was allergic to penicillin and contrast dye. The patient was taking disopyramide phosphate, verapamil and used an albuterol inhaler as needed. She had smoked one pack of cigarettes per day for $20 \mathrm{yr}$. The patient worked as a secretary and walked approximately $3 / 4$ mile to work every day without symptoms.

Past surgical history included total abdominal hysterectomy in 1981 and ureterolithotomy in 1983, both without anaesthetic complication. Physical evaluation revealed a massively obese woman with a II/VI systolic murmur. Breath sounds were clear, without wheezing, rales or rhonchi. Blood chemistry and haematology values were within normal limits. The CXR was of poor quality but normal. The ECG showed normal sinus rhythm at a rate of $67 \mathrm{bpm}$ with left ventricular hypertrophy and nonspecific ST wave abnormalities. Blood pressure was $150 / 80 \mathrm{mmHg}$. Pulmonary function tests were not performed.

The patient was monitored with a three lead ECG, automated blood pressure cuff, pulse oximeter, and cap- 
nography. Anaesthesia was induced with fentanyl $100 \mu \mathrm{g}$, lidocaine $50 \mathrm{mg}$, propofol $200 \mathrm{mg}$ and succinylcholine $100 \mathrm{mg}$. The patient's trachea was intubated on the first attempt, but with difficulty, using a $7 \mathrm{~mm}$ cuffed tracheal tube. Breath sounds were equal bilaterally and the capnogram was normal. Anaesthesia was maintained with oxygen, nitrous oxide, and isoflurane. The patient was positioned on the lithotripsy chair and then transfered to the bath with the water level to her clavicles. Lithotripsy proceeded without incident for approximately 80 $\mathrm{min}$. A total of 2400 shock waves were delivered to the stone. Muscle relaxation was maintained with atracurium. Vital signs during lithotripsy remained stable with the $\mathrm{BP}$ in the range of $125 / 60-140 / 70 \mathrm{mmHg}$ and $\mathrm{O}_{2}$ saturation of $100 \%$. There were no episodes of obstruction or hypoxia. The EDG revealed normal sinus rhythm and the heart rate varied between $75-85 \mathrm{bpm}$. During the procedure the patient received lactated Ringers solution $900 \mathrm{ml} i$. Towards the end of the procedure the muscle paralysis was reversed with neostigmine and glycopyrrolate. Isoflurane and nitrous oxide were discontinued.

Immediately after the patient was lifted from the bath, it was noted that the end tidal $\mathrm{CO}_{2}$ and airway pressures were increased. Pink frothy secretions were noted in the endotracheal tube. Pulse oximetery showed that $\mathrm{O}_{2}$ saturation had decreased from $100 \%$ to $95 \%$ while breathing $100 \% \mathrm{O}_{2}$. There was no arrhythmia. There was an increase in heart rate. The trachea remained intubated and she was transferred to the post-anaesthesia care unit (PACU).

In the PACU the lungs were ventilated with initial ventilator settings of $100 \% \mathrm{O}_{2}$, tidal volume of $700 \mathrm{ml}$, rate of 10 , and PEEP of $5 \mathrm{mmHg}$. Approximately $40 \mathrm{~min}$ after the episode, arterial, and pulmonary artery catheters were inserted. In the PACU, arterial blood gas ( $A B G)$ analysis whilst breathing $100 \% \mathrm{O}_{2}$ showed $\mathrm{pH} 7.20 \mathrm{PCO}_{2}$ $56 \mathrm{mmHg}, \mathrm{PO}_{2} 95 \mathrm{mmHg}$, and $\mathrm{HCO}_{3}{ }^{-}$of $22 \mathrm{meq} \cdot \mathrm{L}^{-1}$. The mean pulmonary capillary wedge pressure (PCWP) was $17 \mathrm{mmHg}$, and the cardiac output was $4.0 \mathrm{~L} \cdot \mathrm{min}^{-1}$. The chest $x$-ray was consistent with congestive heart failure and pulmonary oedema. An esmolol infusion was started and within 90 min the PCWP had decreased to $13 \mathrm{mmHg}$ and the cardiac output was $5.1 \mathrm{~L} \cdot \mathrm{min}^{-1}$. The ABGs were $\mathrm{pH} 7.37, \mathrm{PCO}_{2} 42 \mathrm{mmHg}, \mathrm{PO}_{2} 83 \mathrm{mmHg}$, $\mathrm{HCO}_{3}-22 \mathrm{meq} \cdot \mathrm{L}^{-1}$ with the same respirator settings.

The patient was transferred to the ICU where her ABGs continued to improve and she was weaned from the respirator. The trachea was extubated the next day. The ABG breathing $\mathrm{O}_{2}$ via a nasal canula $\left(\mathrm{O}_{2} 3 \mathrm{~L} \cdot \mathrm{min}^{-1}\right)$ showed pH 7.38, $\mathrm{PCO}_{2} 46 \mathrm{mmHg}, \mathrm{PO}_{2} 96 \mathrm{mmHg} \mathrm{HCO}$ $27 \mathrm{meq} \cdot \mathrm{L}^{-1}$. The patient was able to return to work a few days later and has continued to do well.

\section{Discussion}

To our knowledge this is the first report of pulmonary oedema occurring in a patient with IHSS secondary to ESWL treatment. Hypertrophic subaortic stenosis is characterized by left ventricular hypertrophy with asymmetric septal hypertrophy and a dynamic left ventricular outflow obstruction. ${ }^{2}$ The pathophysiology of this autosomaldominant inherited condition ${ }^{3}$ can be considered as a pressure gradient across the ventricular outflow tract. Three basic mechanisms are involved in the production of outflow obstruction and an increase in gradient, (1) increased left ventricular contractility, (2) decreased afterload, and (3) decreased preload which reduces ventricular volume. Many patients have histories of arrhythmias including supraventricular tachycardia, atrial fibrillation, and ventricular tachycardia. These arrythmias may lead to sudden death. Major symptoms of IHSS include angina, syncope, and congestive heart failure. ${ }^{4}$ The ventricular hypertrophy make these patients susceptible to myocardial ischaemia. Patients with IHSS are often treated with $\beta$-adrenergic blockers or calcium channel blockers to decrease heart rate and ensure longer ventricular filling time. The negative inotropic effects of these drugs decrease hypercontractility and may lessen the outflow gradient. In addition, disopyramide or amiodarone may be used as antiarrythmics.

There have been several reports of pulmonary oedema in patients with IHSS that have been associated with the use of calcium channel blockers. ${ }^{5-7}$ However these episodes occurred shortly after verapamil had been started. 4,5 Our patient had been taking verapamil for years without ill effect.

Immersion of patients during ESWL has haemodynamic, pulmonary and other effects. The patient is placed in a head up position which can be associated with peripheral pooling of blood and diminished venous return to the heart. These changes can be lessened with immersion. ${ }^{8}$ The effects of immersion have been studied in awake volunteers, ${ }^{9-11}$ but there have been few studies of the haemodynamic consequences of immersion in semisupine anaesthetized patients. Transaesophogeal Doppler studies have shown a reduction in cardiac output and increases in mean arterial pressure and systemic vascular resistance (SVR) with immersion for ESWL. ${ }^{12}$ Werner et al. have shown an increase in central venous, and PCWP with immersion and a decrease towards normal values with emersion. ${ }^{13}$

While there has been concern about haemodynamic changes with immersion little has been written concerning the effects of emersion. Lehman et al. reported a death occurring in a 70-yr-old man with a history of coronary artery disease, aortic stenosis, and two previous myocardial infarctions. When the patient was removed from the 
tank he suffered a cardiac arrest. They suggested that due to acute reduction of preload during emersion the patient suffered a decrease in cardiac output and reinfarcted. ${ }^{14}$

We hypothesize that the sudden occurrence of pulmonary oedema in the case reported here was also secondary to the sudden decrease in preload resulting from the rapid emersion of the patient from the ESWL tank. The decrease in preload reduces the size of the outflow tract, producing a transient dynamic obstruction. This acute episode of left sided heart dysfunction led to pulmonary oedema. The acute nature was demonstrated by the sudden increase in inspiratory pressure and decrease in $\mathrm{O}_{2}$ saturation. Unfortunately approximately $40 \mathrm{~min}$ passed from the time of emersion until the first PCWP and cardiac output measurements were obtained. The PCWP may have been much higher at emersion and considerable reequilibration may have occurred before the first measurements were obtained.

Two reports describe adverse occurrences in IHSS patients receiving spinal anaesthesia including myocardial infarction and congestive heart failure. ${ }^{15,16}$ It was postulated that the increased venous capacitance and decreased preload resulting from the effects of spinal anaesthesia on the sympathetic nervous system exacerbated the outflow obstruction. These observations parallel our own.

Treatment of pulmonary oedema in a patient with IHSS must be based on an understanding of the mechanism of cause. Diuretics, digoxin, nitrates or inotropes could all worsen the oedema by provoking further outflow obstruction. A fluid bolus would increase the preload and could help resolve the oedema. It is possible that if the patient was placed back in the tank, allowed to reequilibrate and the water slowly allowed to drain then, the rapid decrease in preload could have been blunted. We used an esmolol infusion to reduce her heart rate, reduce myocardial contractility and allow a prolonged diastolic filling time to reduce the outflow tract obstruction.

In conclusion, we describe a patient with IHSS who developed pulmonary oedema upon emersion from an ESWL tank. Pulmonary oedema was caused by a combination of the patient's unusual pathophysiology and rapid haemodynamic changes induced by emersion. A slower emersion and increased intravenous fluids could have prevented the development of pulmonary oedema.

\section{References}

1 Drach $G W$, Dretler $S$, Fair W, et al. Report of the United States cooperative study of extracorporeal shock wave lithotripsy. J Urol 1986; 135: 1127-33.

2 Maron BJ, Epstein SE. Hypertropic cardiomyopathy. Recent observations regarding the specificity of three hallmarks of the disease: asymmetric septal hypertrophy, septal disorganization and systolic anterior motion of the anterior mitral leaflet. Am J Cardiol 1980; 45: 1-14.

3 Clark CE, Henry WL, Epstein SE. Familial prevalance and genetic transmission of idiopathic hypertropic subaortic stenosis. N Engl J Med 1973; 289: 709-14.

4 Frank $S$, Braunwald E. Idiopathic hypertropic subaortic stenosis: clinical analysis of 126 patients with emphasis on the natural history. Circulation 1968; 37: 759-88.

5 Epstein SE, Rosing DR. Verapamil: its potential for causing serious complications in patients with hypertropic cardiomyopathy. Circulation 1981; 64: 437-41.

6 Lorell $B H$. Use of calcium channel blockers in hypertrophic cardiomyopathy. Am J Med 1985; 78: 43-53.

7 Natarajan D, Sharma SC, Sharma VP. Pulmonary edema with diltiazem in hypertropic obstructive cardiomyopathy. Am Heart J 1990; 120: 229-32.

8 Gauer $O H$, Thron HL. Postural changes in the circulation. In: Hamilton WF, Dow P (Eds.). Handbook of Physiology. Baltimore: Williams and Wilkin, 1965: 2409-39.

9 Arborelius M Jr., Balldin UI, Lilja B, Lundgren CEG. Hemodynamic changes in man during immersion with the head above water. Aerospace Medicine 1972; 43: 592-98.

10 Begin $R$, Epstein M, Sackner MA, Levinson $R$, Dougherty $R$, Duncan $D$. Effects of water immersion to the neck on pulmonary circulation and tissue volume in man. $J$ Appl Physiol 1976; 40: 293-99.

11 Löllgen $H$, von Nieding $G$, Horres $R$. Respiratory and hemodynamic adjustment during head out of water immersion. Int J Sports Med. 1980; 1: 25-9.

12 Rahim B, Colin AS, Ovassapian A, Wilson LA. Hemodynamic responses associated with lithotripsy. Anesth Analg 1987; 66: 254-6.

13 Werner W, Madler C, Keil B, Pollwein B, Laubenthal $H$. Cardiovascular effects of ESWL. In: Gravenstein JS, Peter K (Eds). Extracorpreal Shock-Wave Lithotripsy for Renal Stone Disease. Boston: Butterworths 1986; 101-12.

14 Lehman P, Weber W, Madler C, Schmitz E, Peter K. Anesthesia and ESWL: five years of experience. In: Gravenstein JS, Peter K (Eds.). Extracorporeal Shock-Wave Lithotripsy for Renal Stone Disease. Boston: Butterworth, 1986; 61-8.

15 Loubser $P$, Suh K, Cohen $S$. Adverse effects of spinal anesthesia in a patient with idiopathic hypertrophic subaortic stenosis. Anesthesiology 1984; 60: 228-30.

16 Thompson RC, Liberthson RR, Lowenstein E. Perioperative anesthetic risk of noncardiac surgery in hypertrophic obstructive cardiomyopathy. JAMA; 1985; 254: 2419-21. 